\title{
Práticas do Professor na Discussão de Tarefas que Visam o \\ Desenvolvimento do Sentido de Número: um estudo no Ensino
}

\author{
Básico
}

\section{Teacher's Practices in the Tasks' Discussion Aiming at the Development of Number Sense: a study in an Elementary School}

\author{
Catarina Delgado* \\ Hélia Oliveira** $^{* *}$ \\ Joana Brocardo ${ }^{* * *}$
}

\begin{abstract}
Resumo
Este artigo incide sobre as práticas de um professor do 3..$^{\circ}$ ano do Ensino Básico, no contexto de um projeto colaborativo, visando o desenvolvimento do sentido de número. Concretamente, foca-se nos desafios com que o professor se depara na discussão de tarefas e as suas preocupações relacionadas com o desenvolvimento do sentido de número nos seus alunos. Utilizou-se uma metodologia qualitativa e a recolha de dados incluiu a observação de aulas e sessões de trabalho da equipa do projeto, a análise documental e entrevistas. Os resultados salientam que os principais desafios para o professor na discussão das tarefas são: selecionar os alunos que apresentam as suas estratégias à turma e ordenar essas apresentações, compreender as resoluções dos alunos e "dar-lhes voz". Sobressaem como preocupações associadas ao desenvolvimento do sentido de número a consciencialização de diversas estratégias por parte dos alunos, o estabelecimento da relação entre os contextos e os cálculos e o uso de métodos eficazes de cálculo.
\end{abstract}

Palavras-chave: Práticas do Professor. Desenvolvimento do Sentido de Número. Discussão de Tarefas. Trabalho Colaborativo.

\begin{abstract}
This article focuses on the practices of a third grade primary teacher who participated in a collaborative project, aimed at developing students' number sense. Specifically, it analyzes the challenges that the teacher faced during the tasks' discussion and his concerns related to the development of the students' number sense. We used a qualitative methodology and data collection included observation of classroom and of project team's working sessions, and document analysis and interviews. The results highlight the main challenges that the teacher faces:

\footnotetext{
* Doutora pelo Instituto de Educação da Universidade de Lisboa (IEUL). Professora Adjunta da Escola Superior de Educação do Instituto Politécnico de Setúbal (ESE/IPS), Setúbal, Portugal. Endereço para correspondência: Instituto Politécnico de Setúbal, Campus do IPS, Estefanilha, 2910-761, Setúbal, Portugal. E-mail: catarina.delgado@ese.ips.pt.

** Doutora pela Faculdade de Ciências da Universidade de Lisboa (FC/UL). Professora Auxiliar do Instituto de Educação da Universidade de Lisboa (IEUL). Endereço para correspondência: Instituto de Educação da Universidade de Lisboa, Alameda da Universidade, 1649-013, Lisboa, Portugal. E-mail: hmoliveira@ie.ulisboa.pt.

*** Doutora pela Faculdade de Ciências da Universidade de Lisboa (FC/UL). Professora Coordenadora da Escola Superior de Educação do Instituto Politécnico de Setúbal (ESE/IPS), Setúbal, Portugal e UIDEF, Instituto de Educação, Universidade de Lisboa. Endereço para correspondência: Instituto Politécnico de Setúbal, Campus do IPS, Estefanilha, 2910-761, Setúbal, Portugal.E-mail: joana.brocardo@ese.ips.pt.
} 
deciding on which students' written productions should be presented to the class; choosing the order of students' presentations; understanding students' strategies and being able to 'give them a voice'. The teacher's main concerns regarding the development of the students' number sense that stand out are the awareness of the different strategies that could be used, the identification of relationships between contexts, and calculations and use of effective methods of calculation.

Keywords: Teacher's Practice. Number Sense Development. Tasks’ Discussion. Collaborative Work.

\section{Introdução}

Na literatura atual sobre o ensino da Matemática, em particular no que diz respeito ao tema Números e Operações, destaca-se a importância de orientar o trabalho em torno do mesmo, de modo a promover o desenvolvimento do sentido de número nos alunos (HOWELL; KEMP, 2010). As características das tarefas que visam o desenvolvimento do sentido de número têm constituído a preocupação de alguns autores (BROCARDO; DELGADO, 2009; FOSNOT; DOLK, 2001; SOOD; JITENDRA, 2007). Ainda assim, é reconhecido que as tarefas não predeterminam a qualidade da aprendizagem, estando esta também relacionada com o modo como o professor as explora na sala de aula (STYLIANIDES; STYLIANIDES, 2008). Nesta linha de ideias, e colocando a ênfase no trabalho que é realizado na sala de aula, Markovits (1989) afirma que o desenvolvimento do sentido de número está associado, sobretudo, a "uma forma de ensinar" (p. 80), sendo fundamental compreender as práticas do professor que potenciam esse desenvolvimento (YANG, 2003).

A escassez de estudos focados no professor e que se relacionem com desenvolvimento do sentido de número dos alunos é salientada por Tsao e Lin (2012). Para além de se compreender o entendimento que os professores têm de sentido de número e da importância que lhe atribuem, estes autores realçam como fundamental realizar estudos que permitam compreender as práticas de ensino que potenciam o desenvolvimento do sentido de número dos alunos. Este artigo decorre precisamente de uma pesquisa cujo objetivo, mais amplo, é descrever e analisar as práticas do professor centradas no desenvolvimento do sentido de número dos alunos do $1 .^{\circ}$ ciclo do Ensino Básico ${ }^{1}$, no contexto de um projeto colaborativo de desenvolvimento curricular (DELGADO; BROCARDO; OLIVEIRA, 2014). Em particular, o presente estudo foca-se na discussão da resolução de tarefas com a turma, pretendendo analisar e compreender os desafios com que o professor se depara e as preocupações que sobressaem com aspetos do sentido de número, nesse momento da aula.

\footnotetext{
${ }^{1}$ O 1. ${ }^{\circ}$ ciclo do Ensino Básico, em Portugal, é frequentado por alunos dos 6 aos 9 anos.
} 


\section{Práticas de discussão das tarefas orientadas para o desenvolvimento do sentido de número}

O significado de sentido de número tem despertado o interesse de alguns investigadores nas áreas da Educação Matemática e da Psicologia Cognitiva. Embora o seu entendimento não seja consensual, nas descrições apresentadas por vários autores (ANGHILERI, 2006; BERCH, 2005; MCINTOSH; REYS; REYS, 1992; YANG; REYS; REYS, 2008) destaca-se a ideia de flexibilidade para lidar com problemas numéricos em contextos reais e a sua dimensão pessoal, na aceção que cada indivíduo terá um modo próprio de olhar para os números e de lidar com eles. Reconhecendo esta especificidade de "ser pessoal", McIntosh et al. (1992) assumem a dificuldade em identificar todos as componentes do sentido de número. Consideram, contudo, três grandes áreas através das quais o sentido de número pode ser examinado: (i) o conhecimento e a destreza com os números, (ii) o conhecimento e a destreza com as operações e (iii) a aplicação do conhecimento e da destreza com os números e as operações em situações de cálculo.

Ao pensar numa tarefa ou ao explorá-la com os seus alunos, o professor está centrado na terceira área, ou seja, na aplicação de conhecimento e de destrezas dos alunos a partir do modo como estes compreendem os números e as operações. Esta área inclui o estabelecimento da relação entre os contextos e os cálculos, a consciencialização da existência de múltiplas estratégias, o uso de representações e/ou métodos eficazes e a inclinação para rever os dados e a razoabilidade dos resultados (MCINTOSH et al., 1992).

Encarando o sentido de número como um processo que se desenvolve a partir das experiências pessoais, é legítimo questionar o papel da escola nesse desenvolvimento. Efetivamente são vários os autores que defendem que o sentido de número se desenvolve gradualmente e discutem as abordagens de ensino que suportam o desenvolvimento conceptual do sentido de número de crianças e jovens, considerando que as características do ambiente de sala de aula e o papel do professor são fundamentais para esse desenvolvimento (ANGHILERI, 2006; MARKOVITS; SOWDER, 1994; MENDES; BROCARDO; OLIVEIRA, 2013; YANG, 2003).

Markovits e Sowder (1994) salientam a importância do professor incentivar os alunos a explicar as suas estratégias, a colocar questões e a usar estratégias de outros colegas que se tenham mostrado eficazes. Para Anghileri (2006) é através desta partilha de estratégias e das discussões que ocorrem em torno das mesmas, que a atividade matemática dos alunos é objetivada, ou seja, se transforma num "tópico de conversação" (p. 134). O papel do professor 
será, essencialmente, conduzir esta conversação de modo que, por um lado, as intenções dos alunos subjacentes às suas estratégias se tornem explícitas e, por outro, suscitar a discussão e reflexão sobre essas estratégias (ANGHILERI, 2006). Assim, um modelo de ensino que propicie o desenvolvimento do sentido de número destaca a importância do papel do professor na compreensão conceitual dos alunos, ao colocar questões adequadas, ao ouvir cuidadosamente as suas explicações e ao fornecer pistas que estimulem a sua compreensão sobre os números e as operações (YANG; HSU, 2009).

Apoiar-se no pensamento dos alunos e fazer progredir a discussão de modo que emerjam e sobressaiam ideias matemáticas importantes constituem aspetos associados ao papel do professor que promovem o desenvolvimento do sentido de número dos alunos e, também, a características fundamentais de discussões coletivas que Stein, Engle, Smith e Hughes (2008) designam por matematicamente produtivas. Para orquestrar estas discussões, ou seja, para lidar com as respostas e estratégias dos alunos contribuindo para melhorar e desenvolver a compreensão matemática da turma, Stein et al. (2008) propõem um conjunto de cinco práticas. A antecipação, que ocorre durante a preparação da tarefa, equivale a pensar nas estratégias que poderão ser utilizadas pelos alunos. A monitorização das resoluções, que decorre durante a realização da tarefa por parte dos alunos, constitui uma forma de fornecer ao professor uma perceção sobre as estratégias usadas pelos alunos. A seleção das estratégias que serão apresentadas à turma, que tem subjacente as representações e os processos que o professor considera serem importantes realçar e os objetivos que delineou para a aula. A ordenação das apresentações dos alunos, que tem subjacentes critérios, tais como, começar por apresentar a estratégia que foi usada pela maior parte dos alunos, as resoluções incorretas de modo a esclarecer desde logo mal-entendidos ou optar por sequenciar as resoluções pelo seu nível de estruturação. E, finalmente, o estabelecimento de conexões entre e dentro das diferentes resoluções apresentadas pelos alunos, permitindo estabelecer ligações entre as diferentes representações usadas e a sistematização das ideias matemáticas associadas às resoluções apresentadas. É de salientar que, quando pensamos numa perspetiva de desenvolvimento do sentido de número, a ordem pela qual é sequenciada a apresentação das estratégias constitui um aspeto particularmente importante. Ordená-las da estratégia de nível de estruturação menos elevado para a de mais elevado, permite aos alunos uma reflexão sobre os seus processos de pensamento e os dos colegas, facilitando o estabelecimento de conexões entre as diferentes estratégias (YANG; HSU, 2009).

A orquestração de discussões coletivas produtivas pode colocar verdadeiros desafios ao professor (LAMPERT, 2001; SPEER; WAGNER, 2009). Investigando a sua própria 
prática, Lampert (2001) refere que um dos desafios com que se depara é ser capaz de "extrair" toda a Matemática utilizada pelos alunos, ao mesmo tempo que tem de dar resposta a um conjunto de aspetos que surgem e/ou que considera ser importante atender. Para além da necessidade de criar representações visuais das ideias que estão a ser discutidas através de um registro comum dos contributos da turma, auxiliar alguns alunos em particular, manter o envolvimento dos alunos na atividade matemática e gerir a discussão tendo em conta o tempo que falta para finalizar a aula, esta autora destaca a impossibilidade de solicitar que todos os alunos respondam a uma determinada questão e as ambivalências que surgem associadas à sua seleção. Por um lado, os alunos que se voluntariam e que não são selecionados podem ter um sentimento de frustração. Por outro lado, os que nunca se oferecem para responder constituem também uma preocupação, levando-a a interrogar-se acerca dos motivos desta opção.

Speer e Wagner (2009) advertem que o facto de uma discussão coletiva ser viva e envolver os alunos na partilha de estratégias, não implica que seja uma discussão matemática produtiva. Esta tem de, necessariamente, possuir "substância matemática e progresso" (p. 531). Estes autores consideram que o principal desafio do professor neste momento de exploração das tarefas na sala de aula é promover o desenvolvimento de conceitos matemáticos a partir de ideias informais e, muitas vezes, incipientes dos alunos (SPEER; WAGNER, 2009). Destacam, também, a dificuldade de o professor reconhecer de que modo as estratégias e ideias matemáticas de alguns alunos são relevantes para o objetivo da aula e/ou para o desenvolvimento da compreensão global do tópico de ensino, tendendo a não aproveitar os contributos destes alunos.

A opção por um modelo de ensino que valorize o desenvolvimento do raciocínio dos alunos através de discussões coletivas produtivas exige que o professor "capitalize" essa discussão no sentido de os levar a explicar e justificar matematicamente os seus raciocínios (YACKEL, 2002). Para tal, o professor deverá preocupar-se em criar ambientes de sala de aula que facilitem e promovam o desenvolvimento conceitual dos alunos em Matemática, ou seja, criar uma determinada cultura de sala de aula (YACKEL, 2002). Num estudo sobre a aprendizagem da multiplicação, Mendes et al. (2013) referem que, para além das características das tarefas propostas, o ambiente de sala de aula, ao qual está associado uma certa cultura de inquirição, foi fundamental para o desenvolvimento do sentido de número dos alunos. Tal exige a criação de normas sociais e sociomatemáticas que não se instituem, nem são imediatas (LAMPERT, 2001) e que implicam um processo de negociação que se carateriza pela sua sistematicidade, persistência, contextualização (enraizado nos acontecimentos da aula) e coerência (BOAVIDA, 2005). 


\section{Metodologia}

O estudo do qual decorre este artigo ocorreu no contexto de um projeto colaborativo de desenvolvimento curricular realizado, em Portugal, com dois professores do $3 .^{\circ}$ ano do Ensino Básico e uma investigadora (a primeira autora), ao longo de um ano letivo (DELGADO et al., 2014). Este projeto teve como objetivo aprofundar modos de promover o desenvolvimento do sentido de número dos alunos. Nas sessões de trabalho que ocorriam, em geral, semanalmente, para além de a equipa selecionar/construir tarefas, preparava a exploração na sala de aula dessas tarefas, que incluía a antecipação sobre o modo como os alunos as iriam resolver, e refletia posteriormente sobre a sua exploração na sala de aula, apoiando-se nas produções dos alunos e em episódios da aula previamente selecionados pela investigadora e/ou pelos professores. No âmbito deste projeto, foram exploradas na sala de aula 31 tarefas intencionalmente selecionadas/concebidas para o desenvolvimento do sentido de número dos alunos.

O estudo segue uma abordagem interpretativa, de tipo qualitativo, dado que se valorizam as ações dos participantes e a compreensão do modo como eles próprios interpretam essas ações (COHEN; MANION; MORRISON, 2007). Cada um dos professores que participou no projeto colaborativo constituiu um caso instrumental (STAKE, 2007), construído e estruturado a partir das questões do estudo, da análise dos dados e da revisão da literatura focada na sua prática de desenvolvimento curricular. Este artigo foca-se num dos dois estudos de caso realizados - o caso do professor Manuel.

A recolha os dados envolveu três tipos de métodos $^{1}$ frequentemente usados na investigação qualitativa - a entrevista, a observação participante e a recolha documental. Foram realizadas duas entrevistas semiestruturadas, uma antes do início do projeto e outra após a sua realização, com o objetivo de aceder às perspetivas e práticas dos professores sobre o ensino e a aprendizagem dos números e das operações. Os documentos recolhidos e analisados incluíram, entre outros, produções dos alunos na resolução das tarefas e materiais utilizados pelos professores nas aulas. A observação participante foi realizada: (i) nas sessões de trabalho da equipa (num total de 30), com registo áudio e (ii) na sala de aula do professor (num total de 15 aulas), com registos áudio e vídeo.

\footnotetext{
${ }^{1}$ Neste artigo os dados recolhidos respeitantes às entrevistas, às sessões de trabalho da equipa e às aulas observadas são identificados por $\mathrm{E}, \mathrm{S}$ e $\mathrm{AO}$, respetivamente, seguidos de um número que corresponde à ordem temporal em que ocorreram.
} 
Numa primeira fase, a análise dos dados foi realizada concomitantemente com a sua recolha, permitindo alimentar, não só o desenvolvimento do projeto, como também a investigação que lhe está associada. Numa segunda fase foram definidas duas dimensões de análise de dados. Uma mais diretamente relacionada com aspetos da gestão das discussões coletivas, que incluem as cinco práticas propostas por Stein et al. (2008) para a orquestração deste momento da aula (já explicitadas na secção 2). Uma outra, pensada para contemplar os aspetos específicos relacionados com o sentido de número, corresponde aos elementos que McIntosh et al. (1992) definiram para a terceira área de caracterização do sentido de número, ou seja, para a aplicação do conhecimento e destreza com os números e as operações (também já explicitados na secção 2).

\section{0 caso do professor Manuel}

Manuel é um professor do $1 .^{\circ}$ ciclo com 12 anos de serviço. No início do projeto, ao descrever o modo como decorre a última fase de trabalho em torno das tarefas na sala de aula, assume que esta se caracteriza fundamentalmente por uma correção do trabalho realizado pelos alunos. Afirma que praticamente não existia uma partilha das várias formas de resolução das tarefas e que, este momento, se limitava à apresentação de resoluções corretas, com o intuito de preparar os alunos para utilizar os mesmos procedimentos em tarefas posteriores que exigiam raciocínios idênticos:

Era um pouco a ideia de, não havendo uma só resolução não era dada a oportunidade dos alunos explicarem as diferentes formas de lá chegarem. (...) Não havia um momento de verbalização e de discussão da tarefa. (...) Era explicado... nós resolvíamos no quadro os exercícios e eles acabavam por resolver outros exercícios aplicando as mesmas estratégias (S30, p. 1, 2011).

Com a sua participação no projeto, ao momento de discussão das tarefas passam a estar associadas intenções e ações diferentes daquelas que eram comuns na sua prática de sala de aula, o que pode justificar o facto de os aspetos que valoriza coincidirem com aqueles que lhe trazem novos desafios e constituírem a fonte de algumas tensões. Estes aspetos serão discutidos nos pontos seguintes.

\subsection{Selecionar e sequenciar as resoluções dos alunos}

Numa fase inicial do projeto Manuel começa por selecionar um aluno, ou par de alunos, para apresentar à turma a sua estratégia de resolução da tarefa. A partir daí, espera que 
os demais alunos identifiquem se as suas estratégias são diferentes, ou não, da que já foi apresentada, e caso a considerem diferente solicita-lhes que a apresentem. Ao refletir sobre o momento de discussão na aula da tarefa 1 - Vamos colocar azulejos I, a primeira tarefa explorada no âmbito do projeto, Manuel descreve este processo de seleção dos alunos:

É assim, à medida que vão surgindo as questões e eles vão dizendo, a minha estratégia é esta. Às vezes não se consegue! Mas eu vou tendo o cuidado de dizer, se esta estratégia já foi dita, se já foi mencionada, já não vale a pena estar... A partir dai há uns quantos que têm o seu braço levantado... que vão caindo. Agora quando há muitas [estratégias] diferentes... (S10, p. 6, 2010).

Este professor manifesta, inicialmente, alguma satisfação relativamente a este método de seleção dos alunos, por considerar que habitualmente não existem muitas estratégias diferentes de resolução das tarefas. Contudo, ao refletir conjuntamente com a equipa sobre o momento de discussão da tarefa 1, afirma que este momento "se calhar, não foi tão bem conseguido" (S10, p. 5, 2010), referindo-se às dificuldades em lidar com um grande número de solicitações dos alunos para apresentarem a sua estratégia e à tendência de alguns deles de “inventar" estratégias a que não recorreram, com o intuito de serem escolhidos para as apresentarem à turma. Para este professor foi o que aconteceu, por exemplo, com Miguel quando este afirma ter pensado em $7 \times 5+1$ para calcular o número de azulejos pintados (Figura 1) que era pedido na tarefa, apesar de a sua resolução escrita evidenciar que recorreu ao produto $6 \times 6$ (Figura 2 ).

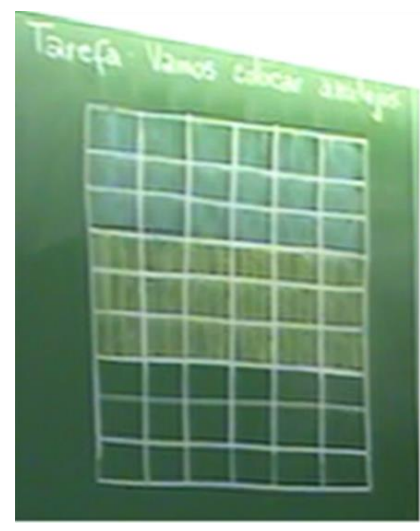

Figura 1 - Painel de azulejos representado, no quadro, por Manuel Fonte: Dados da pesquisa, 2010.

$$
6 \times 6=36
$$

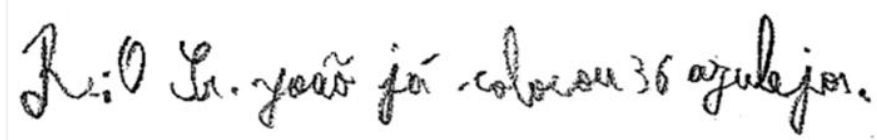

Figura 2 - Registo efetuado por Miguel na resolução da questão 1.1 da tarefa 1 Fonte: Dados da pesquisa, 2010. 
No seguinte episódio de sala de aula, Manuel questiona Miguel sobre o que o terá levado a pensar no produto $7 \times 5$ e como cada um destes fatores se poderiam relacionar com a imagem representada no quadro (Figura 1). Manuel parece pretender que este aluno reconheça que não existe uma relação entre o contexto da tarefa e os cálculos que efetuou.

Professor Manuel: Alguém utilizou outra estratégia?

Miguel: Eu, eu, professor!

Professor Manuel: Diz lá Miguel.

Miguel: 7 vezes 5 mais 1.

Professor Manuel: 7 vezes 5? Eu quando dou uma resposta tenho que saber explicar como pensei. Vem cá explicar.

(O aluno fica em silêncio a olhar para o painel de azulejos previamente desenhado por Manuel - ver Figura 1)

Professor Manuel: De onde veio esse 7? Explica lá ao professor.

(O aluno continua em silêncio)

(AO2, 2010)

Na sessão de trabalho da equipa, ao visionar o episódio correspondente à situação anteriormente transcrita, Manuel vai fazendo alguns comentários: "Ele queria ir ao quadro. (...) É que ele disse aquilo, mas depois não sabia explicar. Olha, cá está ele todo atrapalhado!" (S10, p. 3, 2010). Conclui, afirmando: "Se calhar, da próxima vez, isto já não acontece” (S10, p. 3, 2010). Ao proferir estas palavras, Manuel reconhece que ao ter convidado o aluno a explicar perante a turma a relação entre o contexto da tarefa e os cálculos que efetuou poderá ter constituído uma forma de o dissuadir, e eventualmente outros alunos, de futuramente "inventarem" estratégias.

Considerando que o tempo de discussão da tarefa foi demasiado longo e que, por isso, houve momentos em que a turma mostrou uma certa dispersão, na exploração das tarefas seguintes, Manuel passa a selecionar, logo no momento de realização da tarefa, os alunos que vão apresentar as suas estratégias. Mais à frente no projeto, aquando da realização da tarefa 13 - Embalagens de garrafas de água -, o professor revela preocupar-se em conhecer a diversidade de estratégias que surgiram na aula e quais são os alunos que as utilizaram. Antes de iniciar a discussão da primeira questão desta tarefa, afirma para a turma: "Andei a ver e aqui não há muitas diferenças. Primeiro vem o grupo do Renato” (AO9, 2011). Quando inicia a discussão da segunda questão comenta: "Eu estive a ver e aqui há várias estratégias. Vamos começar pelo grupo do André” (AO9, 2011). Também na última questão desta tarefa, Manuel afirma que "aqui há várias estratégias. Rui e Ana, vocês têm aqui uma explicação que eu vou deixar para o fim. Agora vem a Rute e a Margarida” (AO9, 2011). Estes comentários, para além de evidenciarem que Manuel passa a selecionar os alunos para apresentarem as suas resoluções ao grande grupo de acordo com o conhecimento que possui 
das suas estratégias, revelam também uma preocupação com a ordem pela qual os alunos irão fazê-lo e com a sua explicitação à turma.

A importância que o professor atribui à sequenciação intencional da apresentação das estratégias utilizadas pelos alunos surge associada ao reconhecimento que os momentos de discussão constituem uma oportunidade para eles se aperceberem e compreenderem as estratégias de outros refletirem sobre as que utilizaram e evoluírem para o uso de estratégias mais "eficazes":

É importante que no final exista sempre um momento em que possa haver a partilha, em que possa haver compreensão por parte dos outros e percebam que afinal existem diferentes formas de resolver (...) existem, se calhar, umas que são mais eficazes do que outras, isso obriga-os também a refletir sobre as suas estratégias (E2, p. 5, 2011).

Entendendo por estratégias "eficazes" as que são "mais rápidas e que conduzem a um resultado certo" (S19, p. 2, 2011), preocupa-se em ordenar a apresentação das resoluções dos alunos, tendo em conta estas características. Contudo, efetuar esta sequenciação parece constituir um desafio para Manuel por, durante a aula, não ter tempo suficiente para refletir sobre quais serão efetivamente as estratégias mais e menos eficazes. Por vezes, toma consciência de eventuais mudanças que faria dessa ordenação imediatamente a seguir à discussão da tarefa. Outras vezes, fá-lo na sessão de trabalho da equipa quando analisa mais pormenorizadamente as resoluções dos alunos. Por exemplo, no momento de discussão da primeira questão da tarefa 13, Manuel seleciona três resoluções e organiza a sua apresentação segundo a ordem que consta na Figura 3. 


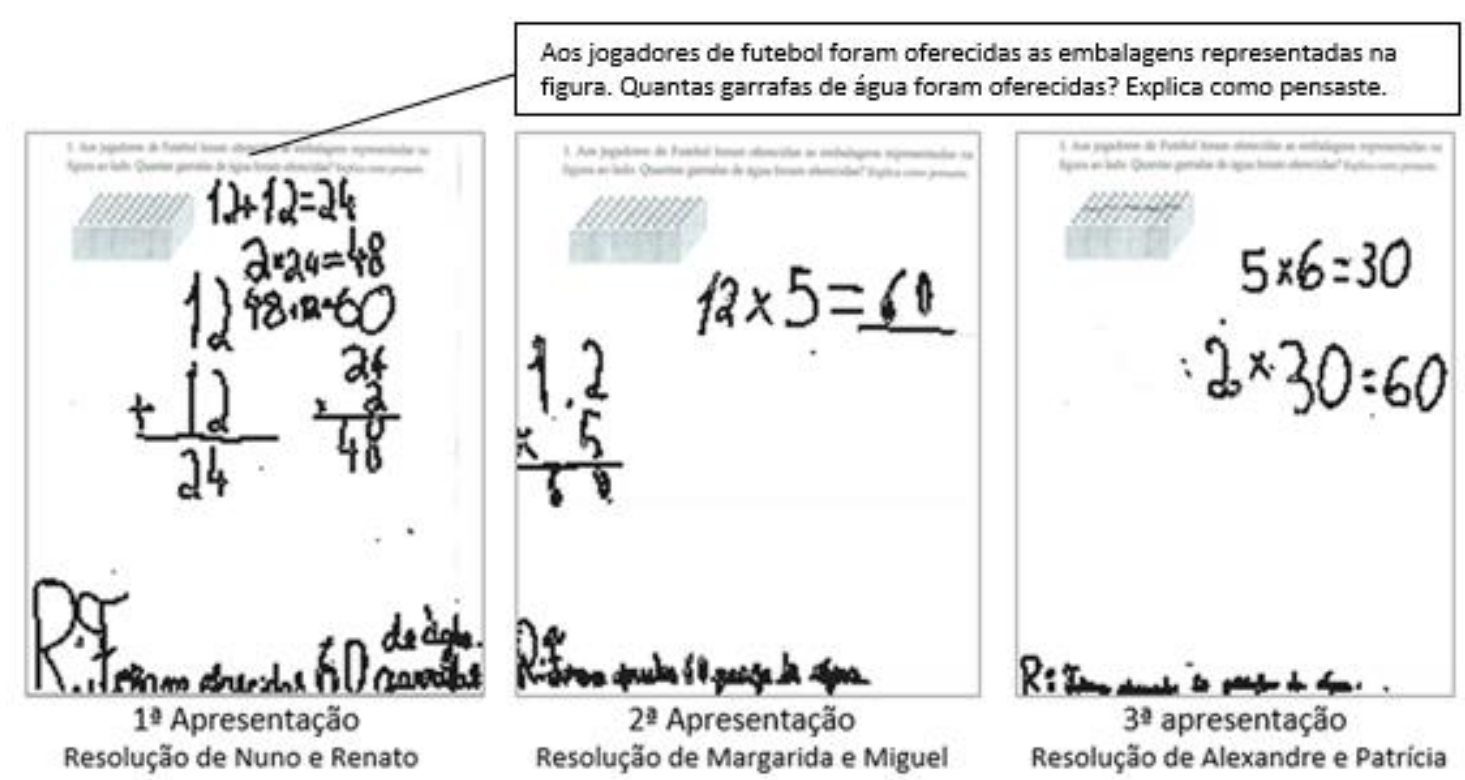

Figura 3 - Ordenação efetuada por Manuel das estratégias usadas pelos alunos, no momento de discussão da questão 1 da tarefa 13

Fonte: Dados da pesquisa, 2011.

Após esta aula terminar, ainda com estas estratégias afixadas no quadro, Manuel comenta: "Se calhar, a ordem seria invertida" (AO9, 2011), apontando para as duas últimas estratégias da Figura 3. Na sessão do projeto em que refletimos sobre esta aula, quando lhe peço para explicar esta afirmação, Manuel refere que manteria a primeira, porque os alunos recorreram à adição, e alteraria a ordem das outras duas, apesar de ambas incluírem o uso da multiplicação. Justifica esta alteração por considerar que a estratégia de Alexandre e Patrícia é menos natural, dado que corresponde a um "olhar" da disposição das garrafas que não é suscitada pela imagem.

Investigadora: Porque é que a ordem seria invertida? Eu não percebi.

Manuel: Nós também temos coisas um bocado estranhas! (risos). Eu acho que aqui [a terceira da Figura 3] era por ser diferente. Porque é assim, claramente, esta [a primeira da Figura 3] era a primeira porque é aditiva e esta [a segunda da Figura 3] era a última.

Investigadora: Porque é que esta era a última?

Manuel: Porquê? Porque está subjacente a multiplicação.

Investigadora: Mas ali [a terceira da Figura 3] também.

Manuel: Também... mas aqui [a terceira da Figura 3] não era suposto estarmos a dividir a caixa.

(S19, p. 3, 2011)

No final da reflexão sobre o modo como ordenou as estratégias Manuel afirma "se tivesse visto com mais calma..." (S19, p. 4, 2011), parecendo, assim, transmitir a ideia de que se tivesse mais tempo para olhar para as produções dos alunos, algumas das suas opções seriam outras.

\subsection{Compreender as resoluções dos alunos}


Também, principalmente numa fase inicial do projeto, só após a aula e no momento de reflexão em equipa é que Manuel se apercebe da existência de algumas resoluções de alunos que apresentam estratégias diferentes e com potencialidades importantes para serem discutidas com toda a turma. Por vezes, surpreende-se com os raciocínios que envolvem e reconhece que teriam sido importantes para a discussão coletiva. Por exemplo, é na sessão de trabalho da equipa que Manuel se apercebe que a estratégia utilizada por Ana (ver Figura 4) na resolução da questão 2 da tarefa 1 é diferente das dos restantes alunos.

Reconhece, também, as eventuais potencialidades desta estratégia para a discussão coletiva ao permitir observar que o produto $6 \times 15$ pode ser calculado através da soma dos produtos $6 \times 4+6 \times 4+6 \times 4+6 \times 3$ e que $4+4+4+3$ corresponde a uma possível decomposição do número 15 (raciocínio associado à propriedade distributiva da multiplicação em relação à adição). A este propósito, e em tom de surpresa, Manuel afirma: "Pois é, ela sabia quanto era $4 \times 6$ e foi dividindo a imagem. Na altura não me ocorreu fazer esta relação" (S10, p. 16, 2010).

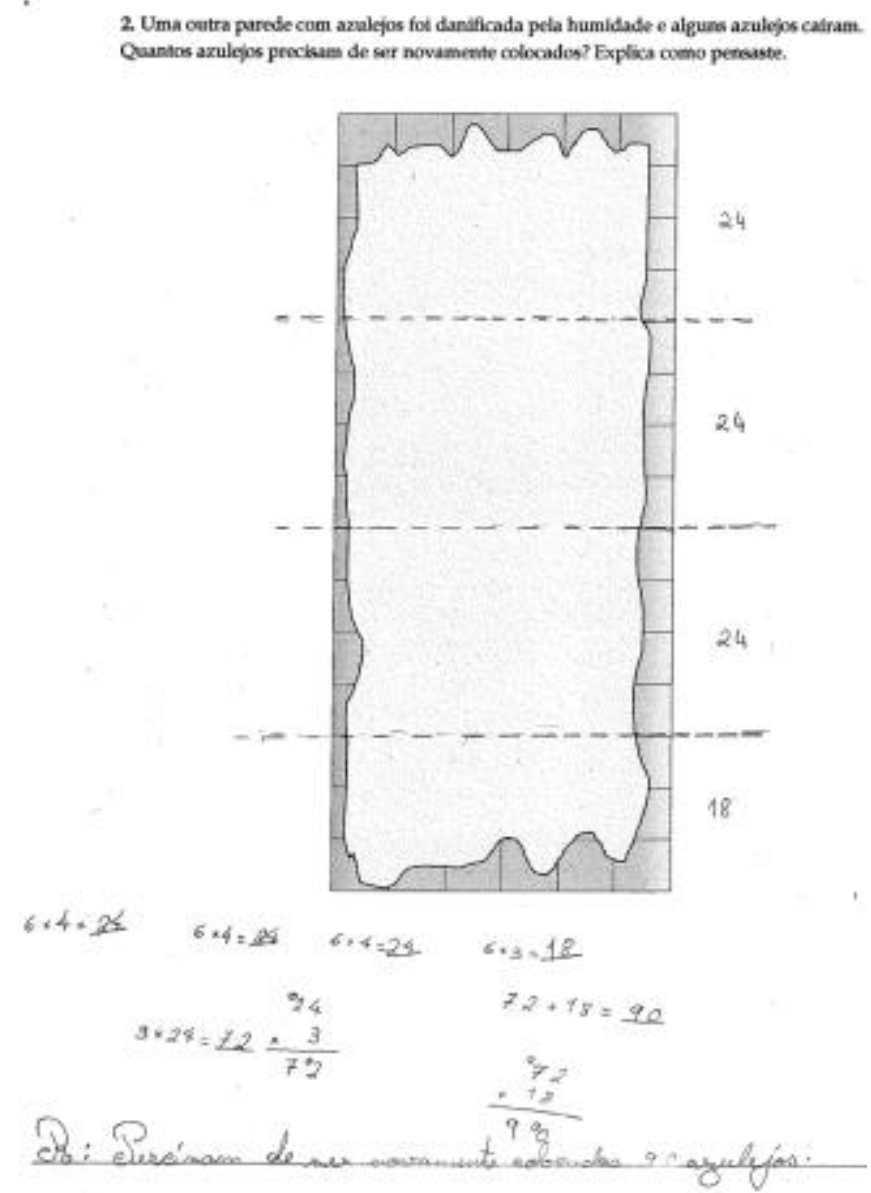

Figura 4 - Registo efetuado por Ana na resolução da questão 2 da tarefa1. Fonte: Dados da pesquisa, 2010. 
Existem, ainda, situações em que Manuel, ao tentar compreender as estratégias dos alunos, acaba por encontrar justificações e significados que, eventualmente, não correspondem ao modo como os alunos pensaram. Por exemplo, na discussão da mesma tarefa e relativamente à primeira questão, quando pede a Rui para explicar porque é que fez $5 \times 6+6=36$ (ver Figura 5), este aluno não responde e, em seguida, Manuel afirma "Então, o Rui viu que até aqui era $5 \times 6$ e juntou esta linha (apontando para o painel de azulejos da Figura 1)" (AO2, 2010).

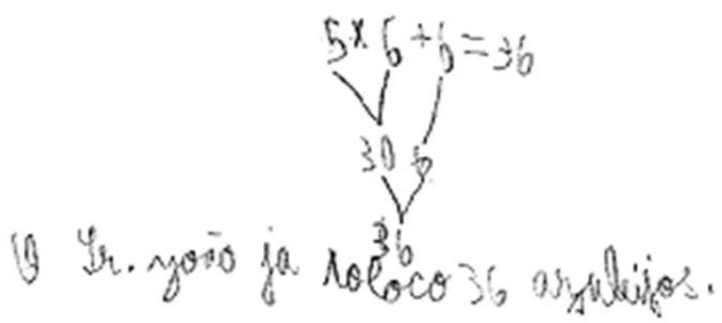

Figura 5 - Registro efetuado por Rui na resolução da questão 1.1 da tarefa 1 Fonte: Dados da pesquisa, 2010.

Ao visualizar o vídeo deste segmento da aula, Manuel afirma que "Acho que ele não visualizou ali [imagem de azulejos da Figura 1], mas percebeu que o produto para chegar ao $6 \times 6$, sabendo o $5 \times 6$ era só adicionar o 6" (S10, p. 15, 2010). Considera, assim, que a expressão apresentada pelo aluno poderá não ter surgido da relação com a imagem, tal como afirmara na aula. Faz uma nova interpretação do raciocínio do aluno, considerando que este terá identificado, por observação da imagem, que existiriam $6 \times 6$ azulejos pintados, efetuando de seguida os cálculos com recurso a um produto conhecido $(5 \times 6)$.

Como resultado da experiência de antecipação das estratégias dos alunos e da sua posterior análise, em particular nas reuniões da equipa, Manuel parece ir adquirindo uma maior facilidade em compreender as estratégias dos alunos. Confessa que umas vezes mostrase preocupado porque as considerava "inventadas", como é o caso da situação descrita no ponto anterior a propósito da estratégia verbalizada por Miguel (ver ponto 4.2 desta secção), ou "estranhas" como classifica a que é apresentada por Margarida (ver Figura 6). 
1. A Inês está a fazer a colecção dos cromos das WITCH e já tem 54 repetidos! Então pensou levá-los para a escola e partilhá-los com 9 amigas do $3^{\circ} \mathrm{A}$ que também coleccionam cromos das WITCH.

- Quantos cromos a Inês vai dar a cada uma?

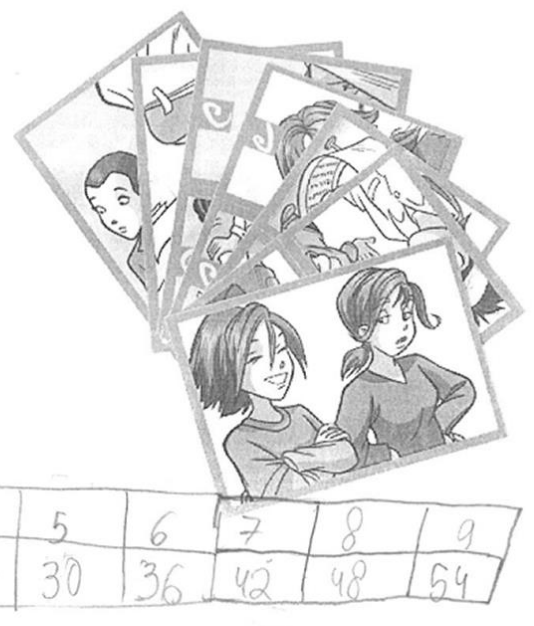

$\mathrm{R}:$

Figura 6 - Registro efetuado por Margarida na resolução da questão 1 da tarefa 21.

Fonte: Dados da pesquisa, 2011.

Apesar de afirmar que não perguntou a Margarida para explicar como pensou, tece alguns comentários sobre esta resolução que mostram segurança no modo como a interpreta. Considera que a tabela que Margarida apresenta nos seus registos foi realizada depois de já saber o resultado do problema.

Manuel: Eu tenho um [aluno] que me faz a tabela...Por acaso era interessante perceber. Tem 9 amigos mas ela vai dando 6 [cromos] a cada um. Um amigo 6 cromos, 2 amigos 12 cromos. (...) Mas para fazer isto ela já tinha que saber que eram 6 [cromos]. (...) Ou fez mentalmente... é estranho!

Investigadora: Era interessante perceber se ela fez primeiro a multiplicação.

Manuel: Só pode! (S22, p. 2, 2011).

\subsection{Dar voz aos alunos}

Quando na última entrevista do estudo, Manuel reflete sobre o momento de discussão das tarefas, reconhece que tem uma certa tendência para centrar em si próprio o discurso da sala de aula. Considera que é importante serem os alunos a apresentar e a explicar as suas estratégias e que devem ouvir e colocar questões aos colegas, afirmando que "este momento deve ser do aluno!" (E2, p. 14, 2011). Assumindo este aspeto como uma dificuldade que sente nestes momentos, na sua perspetiva, a sua intervenção dever-se-ia centrar, sobretudo, na realização de uma síntese dos principais resultados da tarefa:

E, depois, na parte final acabo por monopolizar demasiado esse momento, quando este momento deve ser do aluno! Isso é muito importante, eles ouvirem-se e perceberem... Não quero dizer que eu não o deva fazer, mas, se calhar, devo fazer numa parte final, onde seja quase uma sintese daquilo que foi trabalhado (...) Mas temos de dar espaço aos alunos, isso foi uma dificuldade... (E2, p. 14, 2011). 
No seguinte excerto sobressaem algumas preocupações de Manuel que poderão relacionar-se com os motivos pelos quais tende a conduzir o discurso nestes momentos, apesar de reconhecer que deveriam ser os alunos a assumir o protagonismo.

Eu acho que a turma está muito trabalhada em função daquilo que nós trabalhamos com ela (...) Se este fosse um trabalho feito desde o início, com certeza que eles fariam isso muito facilmente. Agora, é óbvio que este é um processo que para se atingir o objetivo vai demorar mais tempo do que seria feito desde o inicio (...) Acabamos por estar muitas vezes a desmontar os raciocínios deles para os outros perceberem (S12, p. 1, 2010).

Um primeiro motivo relaciona-se com a cultura de sala de aula que, de alguma forma, considera ter desenvolvido com esta turma e que assume ter dificuldade em alterar repentinamente. Manuel reconhece que os alunos estão habituados a dirigir-se ao professor e a ouvir as suas explicações, não a explicitar os seus raciocínios e a colocar questões dirigidas aos colegas. Um segundo motivo parece estar associado à necessidade que sente de que o discurso da sala de aula seja o mais claro possível e matematicamente correto. Considera, por isso, que é importante “desmontar os raciocínios deles" (S12, p. 1, 2010), no sentido de os tornar mais claros para os demais elementos da turma. Ainda nesta sessão, reafirma a dificuldade que os alunos têm em efetuar explicações de forma clara, referindo que "Muitas vezes eles não sabem explicar. É um problema muitas vezes deles!” (S12, p. 1, 2010). Desta forma, é levado a explicar ou clarificar as ideias dos alunos.

\subsection{Promover o desenvolvimento do sentido de número}

No momento de discussão das tarefas observa-se a preocupação de Manuel com aspetos centrais ao desenvolvimento do sentido de número. Desde logo, é bastante visível o seu incentivo a que os alunos justifiquem os cálculos que efetuam, tendo por base o contexto dos problemas. O diálogo que estabelece com Miguel, instando-o a estabelecer a relação entre os cálculos apresentados e a imagem da tarefa (ver o ponto 4.1 desta secção), a justificação de sequenciação das resoluções, focada no tipo de cálculos que a tarefa naturalmente suscita (ver o ponto 4.1 desta secção), e a preocupação em representar no quadro imagens das tarefas, com a intenção de suportarem as explicações dos alunos no momento da discussão destas tarefas (ver Figura 1), são exemplos que ilustram a preocupação deste professor relativamente ao estabelecimento da relação entre os contextos das tarefas e os cálculos.

O modo como organiza e sugere a discussão das tarefas, revela uma crescente atenção a que sejam apresentadas todas as estratégias que são diferentes (ver o ponto 4.1 desta secção), mostrando valorizar a consciencialização da existência de várias estratégias por 
parte dos alunos. Inclusive revela um certo desapontamento quando, nas sessões de trabalho da equipa, se apercebe que não solicitou a apresentação de alguma estratégia que considera interessante, no sentido desta evidenciar o conhecimento e destreza com os números e as operações (ver, por exemplo, o ponto 4.2 desta secção a propósito da estratégia de Ana ilustrada na Figura 4).

Manuel parece encarar o momento de discussão das tarefas como fundamental para o reconhecimento de representações e métodos eficazes por parte dos alunos da turma. Como se pode constatar no ponto 4.1 desta secção, tenta organizar a apresentação das várias estratégias que selecionou, da "menos eficaz" para a "mais eficaz", comparando-as e salientando a importância destas últimas. Por exemplo, a Figura 3 apresenta a ordem pela qual Manuel solicitou a apresentação das estratégias, valorizando, em primeiro lugar, as estratégias que envolvem procedimentos aditivos e, em último, as que incluem procedimentos multiplicativos, havendo a preocupação de, durante a discussão das várias estratégias, salientar a relação entre as operações acima referidas. Também a satisfação que revela com o surgimento da estratégia de Ana e Rui na resolução da tarefa 13 (ver Figura 7), mostra o valor que Manuel atribui ao facto de ter surgido uma estratégia diferente das restantes e que traduz uma ideia importante associada à operação multiplicação.

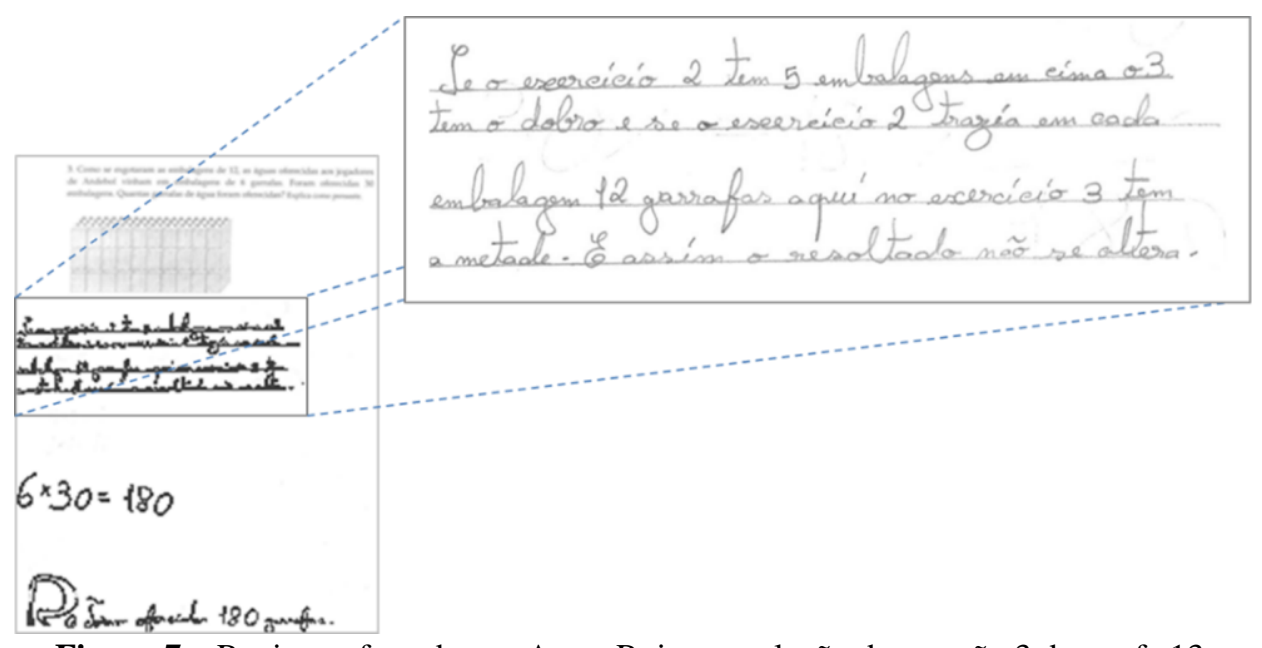

Figura 7 - Registro efetuado por Ana e Rui na resolução da questão 3 da tarefa 13. Fonte: Dados da pesquisa, 2011.

A resolução destes alunos tem implícita a ideia que, numa multiplicação, quando um dos fatores passa ao dobro e o outro a metade, o produto mantém-se. Manuel mostra-se satisfeito por, pelo menos um grupo, ter identificado esta relação, afirmando que "Foi só um [grupo], mas saiu!” (S19, p. 3, 2011).

\section{Discussão e conclusão}


Com a participação no projeto ocorrem mudanças significativas no modo como Manuel organiza o momento de trabalho com os alunos após a realização das tarefas que visam o desenvolvimento do sentido de número. A correção das resoluções dos alunos dá lugar a momentos de discussão das tarefas em que valoriza a apresentação, pelos alunos, de diversas estratégias de resolução das mesmas. Esta mudança é gradual e desencadeadora de alguns desafios. O Quadro 1 caracteriza as práticas de Manuel durante a discussão das tarefas e o modo como perspetiva a resposta aos desafios com que se vai deparando.

A seleção dos alunos que apresentam as suas estratégias à turma constitui um desafio para Manuel que reconhece a dificuldade em lidar com um número elevado de solicitações dos alunos para apresentarem as suas estratégias à turma, por deixar ao critério dos mesmos a identificação das diferenças das estratégias. Revela alguma tensão em deparar-se com a tendência de alguns alunos de "inventarem" supostas resoluções e uma certa preocupação com o facto de se poder esquecer de selecionar alguma estratégia que inclua propriedades e relações numéricas importantes de serem discutidas com a turma. Para este professor, selecionar as estratégias durante o momento de realização da tarefa parece constituir uma solução para dar resposta a este problema, aspeto que é salientado por Stein et al. (2008) como uma estratégia importante de orquestração das discussões coletivas.

\begin{tabular}{|c|c|c|}
\hline & Desafios com que se depara & Resposta aos desafios com que se depara \\
\hline \multirow{3}{*}{ 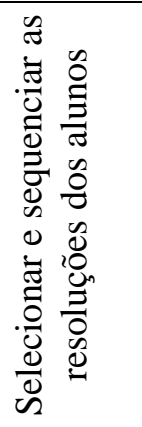 } & \multirow{2}{*}{$\begin{array}{l}\text { Identificar estratégias diferentes } \\
\text { Preocupação com: } \\
\text { - a consciencialização de diversas } \\
\text { estratégias } \\
\text { - a relação entre o contexto da tarefa e os } \\
\text { cálculos }\end{array}$} & $\begin{array}{l}\text { Confirmação prévia de que o aluno usou de } \\
\text { facto a estratégia que registrou }\end{array}$ \\
\hline & & $\begin{array}{l}\text { Levantamento das estratégias no momento } \\
\text { da realização das tarefas }\end{array}$ \\
\hline & $\begin{array}{l}\text { Estabelecer a ordem de eficácia das } \\
\text { estratégias } \\
\text { Preocupação com o uso de representações } \\
\text { elou métodos eficazes de cálculo }\end{array}$ & $\begin{array}{l}\text { Refletir sobre a ordenação das estratégias no } \\
\text { momento de realização das tarefas }\end{array}$ \\
\hline 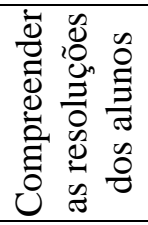 & $\begin{array}{l}\text { Compreender como os alunos pensam } \\
\text { Preocupação com o estabelecimento da } \\
\text { relação entre os contextos e os cálculos }\end{array}$ & $\begin{array}{l}\text { Antecipar as estratégias no momento de } \\
\text { preparação das tarefas }\end{array}$ \\
\hline 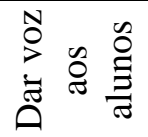 & Discurso claro e matematicamente correto & $\begin{array}{l}\text { Evitar assumir demasiado protagonismo } \\
\text { Incentivar os alunos a clarificar/explicar as } \\
\text { estratégias apresentadas }\end{array}$ \\
\hline
\end{tabular}

Quadro 1 - Desenvolver o sentido de número: práticas de Manuel durante a discussão de tarefas Fonte: Elaborado pelos autores, 2016.

Manuel tenta que a apresentação de resoluções à turma corresponda a uma ordem de eficácia crescente das estratégias, por considerar que tal poderá contribuir para a aprendizagem dos alunos. Esta é uma prática considerada importante por Stein et al. (2008), 
na orquestração das discussões coletivas associadas à exploração de tarefas de Matemática e salientada por Yang e Hsu (2009), quando se trata de explorar tarefas numa perspetiva de desenvolvimento do sentido de número. Contudo, a posteriori, ao refletir sobre a sequência pela qual as diferentes estratégias foram apresentadas, considera que nem sempre esta terá sido a mais adequada. Associa esta dificuldade ao pouco tempo de que dispõe para pensar e interpretar as estratégias dos alunos na sala de aula.

Compreender as resoluções dos alunos é outro dos desafios que se coloca a este professor. Assume a dificuldade em compreender, de imediato, na aula, algumas das resoluções dos alunos e após a mesma identifica estratégias que não se apercebeu que surgiram. Estas constatações acompanham normalmente uma ideia de que a discussão da tarefa não foi totalmente conseguida, do ponto de vista das ideias matemáticas que surgiram, o que corresponde ao que Lampert (2001) descreve como a dificuldade de apresentar e discutir toda a Matemática utilizada pelos alunos durante a exploração de uma tarefa.

Gerir o discurso de sala de aula neste momento de exploração das tarefas constitui também um desafio para este professor. Manuel reconhece uma certa tendência em assumir um grande protagonismo. Por um lado, considera que os alunos, na maioria das vezes, não apresentam um discurso claro e matematicamente correto. Por este motivo, opta por redizer o discurso dos alunos, mas, com alguma frequência, tende a avançar ele próprio com a clarificação/explicação das estratégias apresentadas. Por outro lado, atribui à cultura da sua sala de aula, já instituída, os motivos que estão na base de não existirem mais momentos de interação entre o(s) aluno(s) que apresentam as suas estratégias e os restantes elementos da turma. Efetivamente, uma determinada cultura de sala de aula desenvolve-se através das interações que se estabelecem entre o professor e os alunos e entre estes, num processo de negociação sistemático e continuado de normas sociais e sociomatemáticas (BOAVIDA, 2005).

Manuel procura encontrar respostas para os problemas com que se vai deparando, introduzindo algumas alterações nas suas práticas. Uma forma de organizar e gerir com mais eficácia os momentos de discussão das tarefas passa por alterar as suas práticas durante o momento de realização das mesmas, selecionando e ordenando desde logo as estratégias que virão a ser apresentadas. Desenvolve, também, uma crescente sensibilidade para analisar as estratégias dos alunos, que parece relacionar-se com o trabalho que é realizado em torno da antecipação das estratégias, durante a preparação das tarefas, e com a reflexão acerca das produções dos alunos, após a sua realização. Estes momentos de trabalho da equipa parecem, ainda, contribuir para que este professor adquira, ao longo do projeto, uma maior 
sensibilidade para sequenciar as estratégias tendo em conta a sua eficácia. Estes aspetos coincidem com os argumentos apresentados por vários autores para justificar a importância da antecipação de estratégias na organização de discussões produtivas (STEIN et al., 2008) e na promoção do desenvolvimento do sentido de número dos alunos (YANG; HSU, 2009).

No que respeita às preocupações com os aspetos do sentido de número que sobressaem na discussão das tarefas, evidencia-se o seu cuidado com o estabelecimento da relação entre os contextos e os cálculos pelos constantes pedidos aos alunos para que verbalizem a relação entre os cálculos que realizaram e as características das imagens associadas às tarefas. A preocupação com a consciencialização de diversas estratégias por parte dos alunos é evidenciada, sobretudo, pela importância que é atribuída à seleção de diferentes estratégias para serem discutidas coletivamente. Também a atenção ao uso de representações elou métodos eficazes de cálculo sobressai, essencialmente, através da preocupação em sequenciar as estratégias e da valorização das que se mostram mais eficazes. Estes são três aspetos fundamentais que caraterizam o sentido de número (MCINTOSH et al., 1992).

Foram também evidentes preocupações em envolver os alunos na reflexão sobre a estratégia que usaram e as que poderiam ter usado, e que, segundo McIntosh et al. (1992), faz parte do processo de rever os dados e a razoabilidade do resultado. Contudo, a intenção de suscitar tal reflexão não parece surgir associada a um cuidado com a razoabilidade dos resultados, mas sim com a análise das estratégias e procedimentos usados, que se mostram mais ou menos eficazes, e que envolvem o estabelecimento de eventuais relações numéricas e/ou o uso de determinada(s) propriedade(s) das operações. A não existência de evidências da preocupação deste professor acerca da análise da razoabilidade dos resultados parece estar em consonância com as ideias de Yang et al. (2008), de que este é um aspeto que, habitualmente, os professores pouco valorizam.

A participação deste professor no projeto colaborativo parece ter contribuído para o desenvolvimento da sua compreensão sobre os processos de aprendizagem dos alunos dos números e das operações numa perspetiva de desenvolvimento do sentido de número e para uma maior consciencialização da intencionalidade das suas ações e, por vezes, das implicações dessas ações (DELGADO et al., 2014). A partilha de experiências e a reflexão sobre as práticas de sala de aula, elementos fundamentais deste projeto colaborativo, podem constituir um contexto que sustenta o desenvolvimento de práticas mais complexas, como a que analisamos. Levanta-se, porém, a questão de como sustentar estes processos colaborativos, para além da vida dos projetos, dado que tais práticas levam tempo a consolidar-se. 


\section{Referências}

ANGHILERI, J. Teaching Number Sense. 2. ed. London: Continuum International Publishing Group, 2006. 153 p.

BERCH, D. B. Making sense of number sense: implications for children with mathematical disabilities. Journal of Learning Disabilities, Estados Unidos da América, v. 4, n. 38, p. 333-339, jul./ago. 2005.

BOAVIDA, A. M. A Argumentação em Matemática: investigando o trabalho de duas professoras em contexto de colaboração. 2v. 2005. 489 f. Tese (Doutoramento em Educação) - Faculdade de Ciências, Universidade de Lisboa, Lisboa, 2005.

BROCARDO. J.; DELGADO, C. Desafios e complexidades na concepção e exploração de tarefas para o desenvolvimento do sentido do número. In: ENCONTRO DE INVESTIGAÇÃ̃O EM EDUCAÇÃO MATEMÁTICA, 19., 2009, Vila Real. Atas Números e Estatística: reflectindo no presente, perspectivando o futuro. Vila Real: SPIEM, 2009. p. 1-14.

COHEN, L.; MANION, L.; MORRISON, K. Research Methods in Education. 6. ed. London: Routledge, 2007. 638 p.

DELGADO, C.; BROCARDO, J.; OLIVEIRA, H. Investigar as práticas do professor num contexto de trabalho colaborativo: potencialidades e desafios. Medi@ções, Setúbal, v. 2, n. 3, p. 85-110, 2014.

FOSNOT, C.; DOLK, M. Young Mathematicians at Work: constructing multiplication and division. 1. ed. Portsmouth: Heinemann, 2001. 170 p.

HOWELL, S. C.; KEMP, C. R. Assessing preschool number sense: skills demonstrated by children prior to school entry. Educational Psychology, Washington, v. 4, n. 30, p. 411-429, 2010.

LAMPERT, M. Teaching Problems and the Problems of Teaching. 1. ed. New Haven: Yale University Press, 2001. 496 p.

MARKOVITS, Z. Reactions to the number sense conference. In: SOWDER, J.; SCHAPPELLE, B. (Org.). Establishing Foundations for Research on Number Sense and Related Topics: report of a conference. San Diego: Ed. San Diego State University, 1989. p. 78-81.

MARKOVITS, Z.; SOWDER, J. T. Developing number sense: an intervention study in Grade 7. Journal for Research in Mathematics Education, Reston, v. 1, n. 25, p. 4-29, 1994.

MCINTOSH, A.; REYS, B. J.; REYS, R. E. A proposed framework for examining basic number sense. For the Learning of Mathematics, Canadá, v. 3, n. 12, p. 2-8, 1992.

MENDES, F.; BROCARDO, J.; OLIVEIRA, H. A evolução dos procedimentos usados pelos alunos: contributo de uma experiência de ensino centrada na multiplicação. Quadrante, Lisboa, v. 22, n. 1, p. 133-162, 2013.

SOOD, S. ; JITENDRA, A.K. A comparative analysis of number sense instruction in reform-based and traditional mathematics textbooks. The Journal of Special Education, v. 3, n. 41, p. 145-157, 2007.

SPEER, N. M.; WAGNER, J. F. Knowledge needed by a teacher to provide analytic scaffolding during undergraduate mathematics classroom discussions. Journal for Research in Mathematics Education, Reston, v. 40, n. 5, p. 530-562, 2009. 
STAKE, R. E. A Arte da Investigação com Estudos de Caso. 1. ed. Lisboa: Fundação Calouste Gulbenkian, 2007. 187 p.

STEIN, M. K. et al. Orchestrating productive mathematical discussions: five practices for helping teachers move beyond show and tell. Mathematical Thinking and Learning, EUA, n. 10, p. 313340, 2008.

STYLIANIDES, A. J.; STYLIANIDES, G. J. Studying the classroom implementation of tasks: highlevel mathematical tasks embedded in "real-life" contexts. Teaching and Teacher Education, Reino Unido, n. 24, p. 859-875, 2008.

TSAO, Y. L.; LIN, Y. C. Elementary school teachers' understanding towards the related knowledge of number sense. US-China Education Review B, Illinois, n. 1, p. 17-30, 2012.

YACKEL, E. What we can learn from analyzing the teacher's role in collective argumentation.

Journal of Mathematical Behavior, EUA, n. 21, p. 423-440, 2002.

YANG, D. C. Teaching and learning number sense - an intervention study of fifth grade students in Taiwan. International Journal of Science and Mathematics Education, Dordrecht, n. 1, p. 115-134, 2003.

YANG, D. C.; HSU, C. J. Teaching number sense for 6th graders in Taiwan. International Electronic Journal of Mathematics Education, Den Haag, v. 2, n. 4, p. 92-109, 2009. Disponível em: <file:///C:/Users/toshiba\%20r630/Downloads/IEJME 326 article 5757cfb3c0b46\%20(6).pdf. >. Acesso em: 1 de maio de 2016.

YANG, D. C.; REYS, R. E.;REYS, B. J. Number sense strategies used by pre-service teachers in Taiwan. International Journal of Science and Mathematics Education, Dordrecht, v. 2, n. 7, p. 383-403, 2008.

Submetido em Junho de 2016. Aprovado em Outubro de 2016. 